\title{
Preparation and Properties of Fungal Mycelium Based on Garden Waste
}

\author{
Dong Zou ", Liqiang Gao \\ Hangzhou Institute of Municipal Construction, Hangzhou, China
}

\section{Email address:}

18793060@qq.com (Dong Zou)

${ }^{*}$ Corresponding author

\section{To cite this article:}

Dong Zou, Liqiang Gao. Preparation and Properties of Fungal Mycelium Based on Garden Waste. Science Discovery.

Vol. 8, No. 2, 2020, pp. 43-45. doi: 10.11648/j.sd.20200802.14

Received: April 29, 2020; Accepted: June 7, 2020; Published: June 9, 2020

\begin{abstract}
With the development of urban afforestation, the increasing of garden waste has become a seriously problem. There are a lot of limitations by the traditional approaches to garden waste utilization and therefore it's urgent need to explore a new method for garden waste utilization. To solve the problem of using garden waste, we produce a new composite material called fungal mycelium materials at room temperature which based on garden waste and straw. And the composite material is comprised of a substrate of discrete particles and a network of interconnected mycelia cells bonding the discrete particles together. In order to obtain a shorter growth cycle and more excellent properties of fungal mycelium materials, we mixed garden waste and straw in different proportions with oyster mushroom No. 1. The experimental results show that the fungal mycelium materials with good properties by only garden waste. But the speed of fungal mycelia growth accelerated from 14 days to 12 days, the density of the fungal mycelium material reduced from $0.23 \mathrm{~g} / \mathrm{cm}^{3}$ to $0.18 \mathrm{~g} / \mathrm{cm}^{3}$ and the mechanical properties of the fungal mycelium material improved through adding $20 \mathrm{wt} \%$ straw into the garden waste. The fungal mycelium materials with good mechanical properties, low density, low moisture content and low thermal conductivity could be applied to thermal insulation, packaging and decoration.
\end{abstract}

Keywords: Garden Waste, Resource Utilization, Fungal Mycelium

\section{基于园林废弃物制备的菌丝体及其性能研究}

邹拣 ${ }^{*}$ 高立强

杭州市城市建设科学研究院, 杭州, 中国

邮箱

18793060@qq.com（邹栋）

摘要：随着我国城市绿化进程的加快，园林废弃物日益增多，而目前园林废弃物的资源化利用途径存在着诸多局限，因此 迫切需要探索新方法来实现园林废弃物的资源化利用。本文研究了以园林废弃物以及秸秆作为培养料在室温条件下来生产 食用菌菌丝, 并利用食用菌菌丝将分散的培养料颗粒包裹连接, 从而制备出了一种新型的复合材料一一菌丝体材料。为了 获得更短的菌丝体生长周期以及更佳的材料性能, 将园林废弃物与秸秆以不同比例混合, 并加入平菇秋丰 1 号菌种。实验结 果表明, 单独以园林废弃物作为培养料可以获得性能良好的菌丝体材料, 但是在园林废弃物中添加 $20 \mathrm{wt} \%$ 的秸秆, 可以将菌 丝生长时间从 14 天缩短至 12 天, 菌丝体材料的密度从 $0.23 \mathrm{~g} / \mathrm{cm}^{3}$ 降至 $0.18 \mathrm{~g} / \mathrm{cm}^{3}$, 并且其力学性能也有所改善。该菌丝体材料 具有良好的力学性能，同时兼具低密度、低含水率、低导热系数，可用于包装、隔热以及装饰等多种领域。

关键词：园林废弃物, 资源化利用, 菌丝体 


\section{1. 引言}

园林废弃物是指园林植物自然调落或人工修剪所产 生的残体，包括树叶、枝条、草屑、残花等，其含有大量 的木质素、纤维素、半纤维素等有机质。传统的园林废弃 物处理方式主要是填埋或焚烧, 这不仅会加重政府财政负 担, 更是带来极大的生态环境压力[1-4]。目前, 园林废弃 物资源化利用是较理想的解决途径, 主要方式有堆肥[5-7]、 生物质能源 [8-9]、地表覆盖物[10-12]、菌棒[13]等。

利用真菌菌丝将农业废弃物颗粒连接起来, 制成菌丝 体复合材料, 可用作包装材料、隔热材料、复合板材等 [14-15]。但目前原料主要采用各类秸秆, 而以园林废弃物 作为培养基质, 利用真菌生长而生产菌丝体复合材料, 尚 未见到这方面的研究报道。本文对园林废弃物作为主要培 养基质来生长菌丝体材料进行了研究, 为园林废弃物的资 源化利用尝试新的方向。

\section{2. 材料与方法}

\section{1. 主要仪器设备}

型号为HVE-50的压力蒸汽灭菌器, 鼓风烘干机, 粉 碎机。

\section{2. 实验材料}

菌种为平菇秋丰 1 号; 培养料为粉碎成 $0.5-2 \mathrm{~cm}$ 的园林 废弃物和高粱秸秆, 辅料为麦麸和石膏。

\section{3. 实验方法与过程}

\subsection{1. 装料及配比}

采用 $800 \mathrm{~mL}$ 的聚丙烯菌种瓶, 每瓶装量 $250 \mathrm{~g}$ 。本实验 的培养料的配比方式有 5 种, 详见下表:

表1 培养料的组成配方。

\begin{tabular}{|c|c|c|c|c|c|}
\hline 配方 & $\begin{array}{l}\text { 园林树枝 } \\
\text { (g) }\end{array}$ & 秸秆（g） & 麦秩（g） & 石膏（g） & 水 $(\mathrm{g})$ \\
\hline 配方 1 & 600 & - & 30 & 6 & 900 \\
\hline 配方 2 & 540 & 60 & 30 & 6 & 900 \\
\hline 配方3 & 480 & 120 & 30 & 6 & 900 \\
\hline 配方4 & 420 & 180 & 30 & 6 & 900 \\
\hline
\end{tabular}

\begin{tabular}{llllll}
\hline 配方 & $\begin{array}{c}\text { 园林树枝 } \\
(\mathbf{g})\end{array}$ & 秸秆 $(\mathbf{g})$ & 麦焃 $(\mathbf{g})$ & 石高 $(\mathbf{g})$ & 水 $(\mathbf{g})$ \\
\hline 配方 5 & 360 & 240 & 30 & 6 & 900 \\
\hline
\end{tabular}

\subsection{2. 灭菌及接种}

将培养料装入菌种瓶后, 放入立式压力蒸汽灭菌器中, 按照压力为 $0.1 \mathrm{MPa}$, 温度为 $121^{\circ} \mathrm{C}$, 灭菌时间为 $120 \mathrm{~min}$ 的 方式进行灭菌。灭菌后, 将菌种瓶放接种室自然冷却。冷 却至 $30^{\circ} \mathrm{C}$ 以下, 在超净工作台上接入菌种。

\subsection{3. 菌丝体培养及成型}

将接种后的菌种瓶放入 $25^{\circ} \mathrm{C}$ 的培养箱中, 14 天后, 培 养料表面基本布满白色菌丝。取出, 烘干, 定型, 即可得 到菌丝体材料。

\section{3. 结果与讨论}

\section{1. 菌丝生长速度}

将平菇秋丰 1 号菌种放入 5 种不同的培养基中生长, 实 验结果如表2所示。从表 2 中可以看到, 平菇秋丰 1 号菌种 在以园林废弃物为主的培养料中, 生长速度很快, 两周左 右菌种瓶中就已经布满了白色菌丝, 而且菌丝也都非常浓 密。少量秸秆的加入能改善单独以园林废弃物为培养基 （配方 1) 的菌丝生长情况, 随着秸秆含量的增加, 菌丝 生长速度表现为先增加后减小, 此现象说明秸秆中的营养 成分能提供有益的补充, 但随着秸秆含量的持续增加, 改 变了培养料的物理堆积状态, 反而影响了菌丝的生长。从 菌丝体的浓密程度来看, 除了秸秆含量最高的配方 5 表现 得稍差一些, 其余配方的菌丝体浓密程度都很高。

表2 各配方的菌丝生长情况。

\begin{tabular}{lll}
\hline 配方 & 菌丝生长速度 $(\mathbf{d})$ & 菌丝密度 \\
\hline 配方 1 & 14 & ++++ \\
配方 2 & 13 & ++++ \\
配方 3 & 12 & ++++ \\
配方 4 & 14 & ++++ \\
配方 5 & 17 & +++ \\
\hline
\end{tabular}

注: ++++表示菌丝体很浓密, +++表示菌丝体浓密。

表3 菌丝体的性能。

\begin{tabular}{lllllll}
\hline 配方 & 密度 $\left(\mathbf{g} / \mathbf{c m}^{\mathbf{3}}\right)$ & 抗压强度 $(\mathbf{K P a})$ & 断裂弯曲应力 $(\mathbf{N})$ & 含水率 $(\mathbf{\%})$ & 吸水率 $(\mathbf{\%})$ & 导热系数 $(\mathbf{W} / \mathbf{m} \cdot \mathbf{K})$ \\
\hline 配方 1 & 0.23 & 170 & 34.2 & 8.0 & 18.6 & 0.08 \\
配方2 & 0.2 & 174 & 35.1 & 8.2 & 17.5 & 0.08 \\
配方3 & 0.18 & 172 & 34.8 & 8.2 & 18.2 & 0.08 \\
配方4 & 0.17 & 175 & 35.2 & 8.1 & 17.8 & 0.09 \\
配方 5 & 0.15 & 151 & 25.9 & 9.8 & 25.3 & 0.08 \\
\hline
\end{tabular}

\section{2. 菌丝体的性能}

从表3可以看到, 随着配方中秸秆含量的不断增加, 菌丝体的密度也逐步减小, 这显然是由于秸秆的密度要小 于园林废弃物。其它指标包括抗压强度、断裂弯曲应力、
含水率、吸水率在配方 $1-4$ 中都非常接近, 而配方 5 的抗 压强度和断裂弯曲应力明显低于其它 4 组配方, 含水率和 吸水率则高于其余 4 组配方。这是因为配方 $1-4$ 的菌丝生 长浓密, 已经把分散的颗粒紧紧连接在一起了, 而配方5 的菌丝生长相对稍差一些, 从而导致了菌丝体的致密程度 
也相应变差, 最终影响了菌丝体的性能。而菌丝体的导热 系数基本都保持在 $0.08 \mathrm{~W} / \mathrm{m} \cdot \mathrm{K}$, 配方 5 与其余配方并没有 明显差异, 这是因为其含水率高会增大导热系数而致密度 低则会减小导热系数, 两者相结合导致其导热系数基本不 变。

从表3中的力学性能来看, 该菌丝体材料性能介于硬 质泡沫与密度板材之间, 同时其具有低密度、低含水率、 低导热系数, 因此无论是用作包装材料、装饰材料或隔热 材料, 都具有很好的应用前景。

\section{4. 结论}

本文研究了以园林废弃物作为主要培养料来生产菌 丝体材料, 为进一步将园林废弃物资源化利用奠定了基础。 试验结果表明, 以园林废弃物作为主要培养料, 平菇秋丰 1 号作为菌种, 两周左右即可形成致密的菌丝体材料。秸 秆添加量在 $30 \mathrm{wt} \%$ 以内, 不影响菌丝的生长浓密程度, 也 不会影响菌丝体材料的性能, 但可以调节菌丝体材料的密 度。菌丝体材料性能良好, 可用作包装材料、装饰材料或 隔热材料，是园林废弃物资源化利用的理想途径。

\section{参考文献}

[1] 卢蔚. 谈园林垃圾的资源化利用 [J].山西建筑, 2013, 39(30): 192-193.

[2] 刘明清, 李康敏, 韩静磊等. 小型焚烧炉处理园林垃圾 PCDD/Fs 排放及控制 [J]. 中国环境科学， 2013, 33(S1):74-78.
[3] 春建伟, 刘鸿赝, 梁顺文等. 深圳市园林绿化垃圾的产生 和收集现状及处理对策 [J]. 环境卫生工程, 2009, 17(1):47-49.

[4] 洪霞, 张璐. 杭州西湖景区园林绿化废弃物资源调研 [J]. 现 代园艺，2015,3:9-10.

[5] 席北斗, 刘鸿亮, 白庆中等. 堆肥中纤维素和木质素的生 物降解研究现状 [J]. 环境污染治理技术与设备, 2002, 3(3):19-23.

[6] 杨宁, 刘红权, 孙芳芳. 不同菌剂对园林绿化废弃物堆肥 效果的影响[J]. 林业科技开发, 2015, 29(4):53-57.

[7] 赵怀宝, 邓新兵, 吉向平等. 园林废弃物堆肥适宜菌剂的 笁选[J].琼州学院学报, 2015, 22(2):85-89.

[8] 刘雪静. 园林废弃物与新能源一生物质能处理的新方式 $[\mathrm{J}]$. 现代园艺，2012, 4:88-89.

[9] 白婧, 沈洪艳, 董世鬼等. 高速公路绿化废弃物的生态利 用与处理 [J]. 安徽农业科学, 2010,38（34）：19488-19490.

[10] 王水浪, 余洪文, 吴晓华. 城市园林绿色废弃物处理现状 及对策分析 [J]. 2013, 3:79-82.

[11] 孙克君, 林鸿辉. 园林垃圾变基质是节约型园林绿化发展 的新途径[J]. 园林科技，2008,108（2）：33-35.

[12] 王莹. 园林绿化废弃物处理的现状及政策[J]. 农业与技术, 2017, 37 (2) : 219.

[13] 王鹏, 王文静, 虎嘉祥等. 悬铃木落叶生物质资源在平菇 栽培中的应用研究[J]. 河南科学, 2016, 34(4):517-520.

[14] 吴豪, 赵鹏, 章琦等. 基于菌丝体的缓冲包装材料制备及 性能研究[J]. 浙江科技学院学报, 2015, 27(1):22-27.

[15] 间薇, 于兰芳, 李晓等. 基于菌丝体的生物质保温材料研 究现状[J]. 林产工业, 2019, 56(12):34-37. 